\title{
BMJ Open Assessing health-related quality of life and health utilities in patients with chronic hepatitis B-related diseases in China: a cross-sectional study
}

\author{
Meng Zhang (D) , ${ }^{1,2}$ Yaoguang Li, ${ }^{1}$ Zihao Fan, ${ }^{3}$ Dongqi Shen, ${ }^{4}$ Xueying Huang, ${ }^{5}$ \\ Qi Yu, ${ }^{6}$ Mei Liu, ${ }^{5}$ Feng Ren, ${ }^{3}$ Xiao Wang, ${ }^{2,7}$ Liping Dai, ${ }^{2,7}$ Peng Wang, ${ }^{1,2}$ Hua Ye, ${ }^{1,2}$ \\ Jianxiang Shi, ${ }^{2,7}$ Xiaoang Yang, ${ }^{7}$ Shunxiang Zhang, ${ }^{1,7}$ Jianying Zhang ${ }^{1,7}$
}

To cite: Zhang M, Li Y, Fan Z, et al. Assessing health-related quality of life and health utilities in patients with chronic hepatitis B-related diseases in China: a cross-sectional study. BMJ Open 2021;11:e047475. doi:10.1136/ bmjopen-2020-047475

- Prepublication history and additional supplemental material for this paper are available online. To view these files, please visit the journal online (http://dx.doi.org/10.1136/ bmjopen-2020-047475)

Received 02 December 2020 Accepted 31 August 2021
Check for updates

(C) Author(s) (or their employer(s)) 2021. Re-use permitted under CC BY-NC. No commercial re-use. See rights and permissions. Published by BMJ.

For numbered affiliations see end of article.

Correspondence to Dr Jianying Zhang; jianyingzhang@hotmail.com and Dr Shunxiang Zhang; zhangsx@szcdc.net

\section{ABSTRACT}

Objectives The health-related quality of life (HRQoL) and utilities of patients with chronic hepatitis B (CHB) virus infection, including compensated cirrhosis (CC), decompensated cirrhosis (DC) and different stages of hepatocellular carcinoma ( $\mathrm{HCC}$ ), have not been well described in China. This study aimed to evaluate HRQOL and utilities and provide parameters for the economic evaluation of CHB-related diseases.

Methods We conducted a multicentre cross-sectional and study to measure the HRQoL of patients with $\mathrm{CHB}$, CC, DC and HCC using the Chinese short form (SF) 36 health survey V.2. The utilities were extracted based on the SF-six dimension scoring model. Multivariable regression analyses identified the effects on HRQoL. Results A total of 1071 patients (639 with CHB, 125 with $\mathrm{CC}, 85$ with $\mathrm{DC}$ and 222 with $\mathrm{HCC}$ ) were invited to complete the questionnaire. Physical HRQoL was not impaired in the CHB stage, while mental HRQoL was significantly impaired. Physical composite summary scores have a more significant decrease than mental composite summary scores at the advanced stages (CC, DC and HCC). The utility scores of CHB only, CC, DC and HCC were $0.773,0.750,0.683$ and 0.640 , respectively. The utility scores in the early, middle and terminal stages of HCC were $0.656,0.635$ and 0.615 , respectively.

Conclusion Slowing the progress of CHB-related diseases and providing psychological support early are the key points to improving the quality of life with the diseases. The utility values estimated in this study can provide a vital instrument for cost-effectiveness studies on CHB-related diseases.

\section{INTRODUCTION}

The high prevalence of chronic hepatitis B (CHB) calls for a significant global health concern. WHO member states have committed to global elimination with targets to reduce attributable deaths by $65 \%$ by the year 2030. ${ }^{2}$ Although new infectors with hepatitis B virus (HBV) have significantly declined among low age groups because of
Strengths and limitations of this study

- This multicentre cross-sectional survey aims to measure the health-related quality of life and health utility value of patients with hepatitis B-related diseases in China.

- Large-scale survey of 1071 patients with hepatitis B-related diseases, assessing the health-related quality of life and utility values of different subgroups including different demographic sociological characteristics and, for the first time, the clinical stages of hepatocellular carcinoma.

- The adjustment has been made for confounders including the demographic sociological characteristics.

- All patients recruited from three tertiary hospitals may lead to selection bias.

- The health utility scores converted from short form (SF) 36 health survey V.2 based on the SF-six dimension scoring model for the Hong Kong Chinese population may differ from the mainland Chinese population.

hepatitis B vaccination campaigns in China, there is still a heavy burden in adults caused by CHB-related diseases, including compensated cirrhosis (CC), decompensated cirrhosis (DC) and different stages of hepatocellular carcinoma (HCC) ${ }^{34}$ It is not enough to draw increased attention to the social and health concerns of the diseases only through clinical indicators such as morbidity and mortality. The health-related quality of life (HRQoL) of CHB-related patients, which represent the patients' subjective feelings, should be accurately evaluated. ${ }^{5}$

Patients with CHB-related disease undergo decreased HRQoL, an essential patient-report outcome to evaluate any long-term therapeutic intervention and disease progression. Impaired HRQoL may be reflected in both psychological and physical aspects. To our knowledge, several 
studies have shown the HRQoL of patients with CHBrelated disease, but it is still uncertain whether the HRQoL of patients with CHB is similar to that of the normal population. ${ }^{6-11}$ Moreover, these studies only focused on Chinese patients with CHB and liver cirrhosis; few studies have focused on HCC or different stages of HCG. ${ }^{6}$ In addition, these studies were carried out almost 10 years ago, and HRQoL may change with societal development. Therefore, previous studies may not be able to explain the current HRQoL of patients with CHB-related diseases accurately.

Apart from being an index of patients' health and health utility, a preference indicator converted from HRQoL can be used in economic evaluation. The health utility value is a comprehensive indicator that integrates multiple dimensions and values full health as a score of one and death as a score of zero. The utility score is widely used to measure qualityadjusted life years in cost-effectiveness analyses. Owing to advances in early diagnosis by imaging and biomarkers, HCC can be detected at an early stage. ${ }^{12}$ To improve the credibility of the cost-effectiveness analysis results, the health status in the Markov model is often divided according to the stages of HCG. ${ }^{13} 14$ When cost-effectiveness analysis focuses on antiviral treatment for patients with CHB-related disease, the utility scores of the patients with different characteristics are also required. The utility value is essential to the results of cost-effectiveness analyses, and a systematic review demonstrated that changes in utility should be used to test in sensitivity analysis. ${ }^{15}$ Few studies have described the health utility value of patients with HCC in various stages or with different characteristics in China.

The short form-36 V.2 (SF-36v2) health survey is widely used for HRQoL measures. The short form-six dimension (SF-6D) can be used to extract items from the SF-36 for preference-based valuation. Additionally, since differences in culture, economy and lifestyle are likely to imfact HRQoL and health utility, studies of Chinese HRQoL and health utility should be converted based on Chinese population-based norms. ${ }^{69}$ The primary aim of this study was to evaluate the HRQoL of CHB-related diseases and the association between HRQoL and sociodemographic and clinical characteristics. The secondary aim was to extract the health utility score of patients with CHB-related disease, including CHB, CC, DC and stages of HCC. The results will allow us to understand the current health status of patients with CHB-related disease in China, and the health utility scores will play a vital role in measuring the cost-effectiveness of clinical and policy interventions for CHB-related diseases in China.

\section{METHODS}

\section{Patient selection}

This was a cross-sectional and multicentrer study involving the clinical liver departments of three tertiary hospitals in China (two in Zhengzhou and one in Beijing). Consecutive CHB-related disease outpatients and HBV-related HCC inpatients were enrolled between July 2019 and January 2020. All patients had tested positive for hepatitis B surface antigen for more than 6 months. ${ }^{16}$ Patients with other chronic diseases (eg, chronic cardiovascular disease or diabetes) or infection with other viruses (eg, hepatitis $\mathrm{C}$ virus or HIV) were excluded. Patients younger than 18 years old or over 80 years old were also excluded.

\section{Data collection}

Each patient completed the Chinese SF-36v2 and provided his or her sociodemographic and disease characteristics data. The SF-36v2 is a widely used HRQoL questionnaire and has been proven to be suitable for the Chinese population. It contains 36 items that can measure eight scales of HRQoL: physical function (PF), role physical (RP), bodily pain (BP), general health $(\mathrm{GH})$, vitality $(\mathrm{VT})$, social functioning (SF), role-emotional (RE) and mental health $(\mathrm{MH})$. The scores of the eight scales were aggregated into two summary scores based on the Standardisation of Chinese norms with a population mean of 50 and an SD of $10 .{ }^{17}$ The two summary scores are the physical composite summary (PCS) and mental composite summary (MCS). The utility scores were converted from SF-36v2 based on the SF-6D scoring model for the Hong Kong Chinese population established and validated by McGhee et $^{1} \mathrm{l}^{18} 1^{9}$

The CHB-related disease was characterised according to stages: CHB, CC, DC and HCC. Patients with CC or DC were diagnosed by Child-Pugh score. ${ }^{20}$ Patients with HCC in early, middle or terminal stages were based on Barcelona clinic liver cancer (BCLC): BCLC (0/A), BCLC (B) and BCLC $(\mathrm{C} / \mathrm{D}) \cdot{ }^{21}$ Utility scores were also classified and calculated according to sociodemographic and disease characteristics.

\section{Statistical analysis}

For descriptive analysis of the study, categorical variables were described using proportions and continuous variables using the mean with $\mathrm{SD}$ and median with IQR. Comparisons among patients with CHB, CC, DC and HCC were carried out by the $\chi^{2}$ test for categorical variables and the Wilcoxon rank-sum test for non-normally distributed continuous variables. In addition, multivriable regression analyses were conducted with PCS and MCS as dependent variables, adjusting for sociodemographic characteristics as possible confounders to investigate the effects of stage of disease and disease characteristics on HRQoL. All statistical analyses were performed using SPSS V.21.0 statistical software (IBM Corp.), and p values below 0.05 were considered statistically significant. 


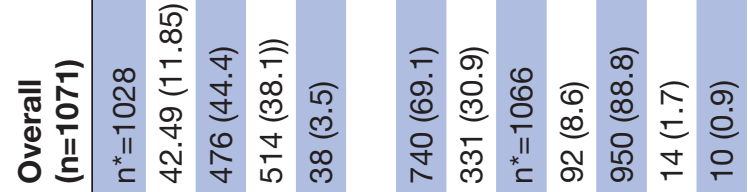

ণิ

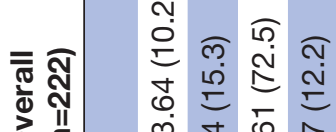

ठี

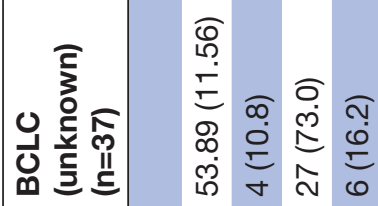

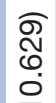

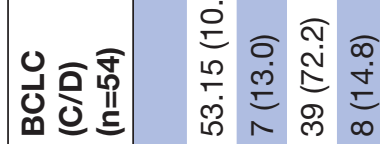

ब0

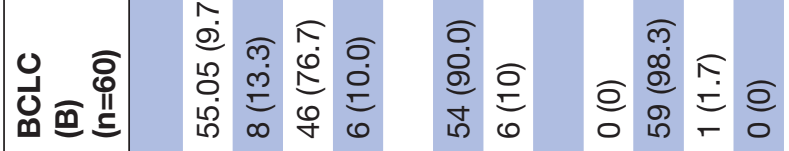

बํ.

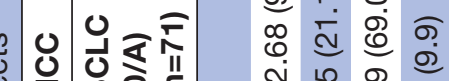

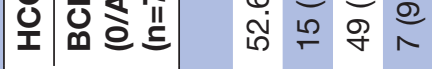

छ

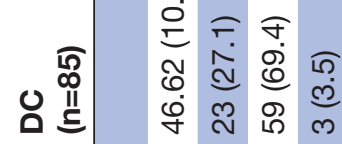

ल)

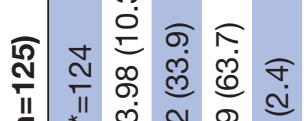

ن III

สิ ชุ ช.

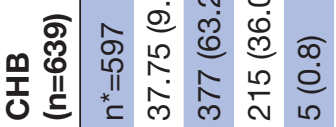

\section{so}

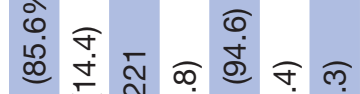

吕 N

כִ

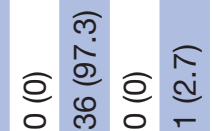

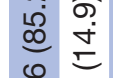

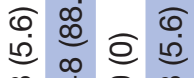

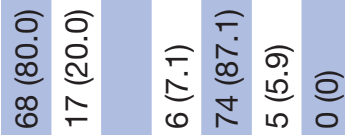

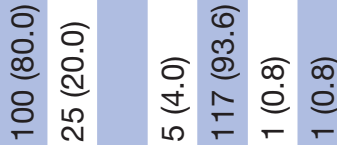

๓)

गु

o
लำ

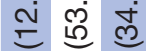

ले

$\widehat{\infty} \widehat{\infty}$

ले

$\underset{\sim}{\sim} \frac{\omega}{n}$

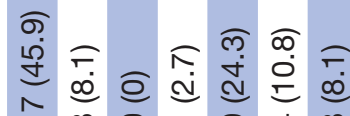

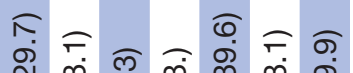

ลิ

ㅇำ

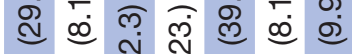

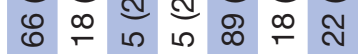

స़ं

읻

สุล क़ สุ

卢

অ

กิ

ลั

ल \&

๙

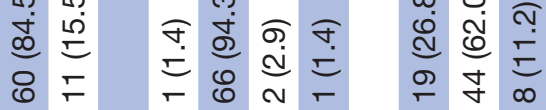

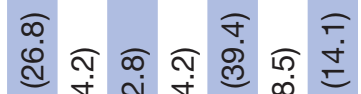

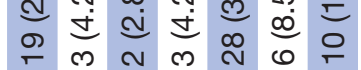

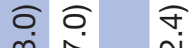

กิ స్ ల్ల

츠으 뜬

ब न

这

$\because$ L

कิ

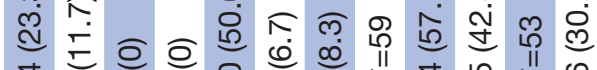

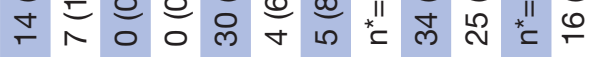

ธิ

¿े

든 กิ

๑

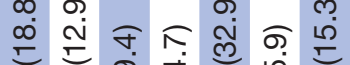

ơ

สิ สิ

过昌 迎

ㅇํ ล

ธิ

을 ญ

눈

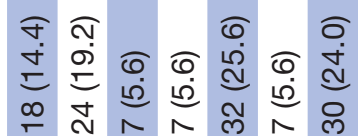

ธก क़ ल

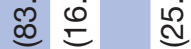

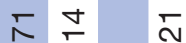

लุ ต़

守金这

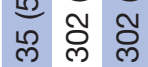

จ

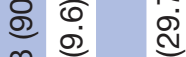

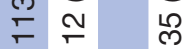

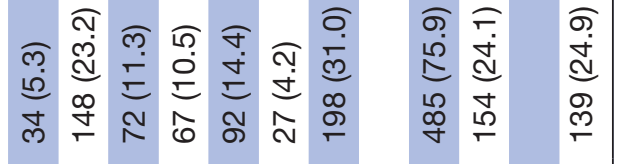

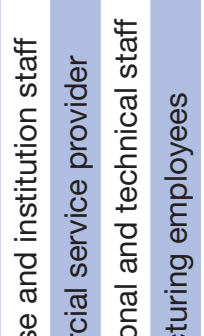

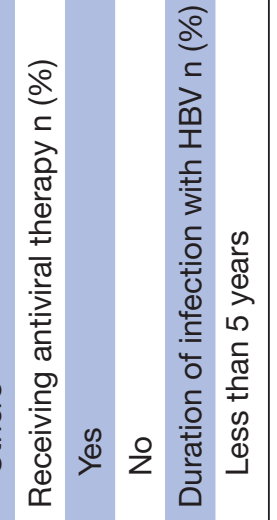




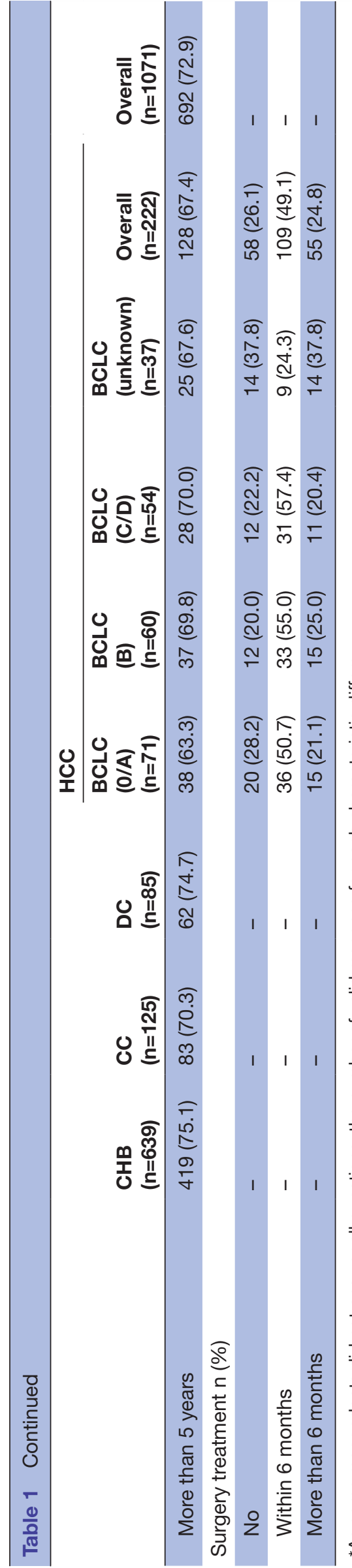

Patient and public involvement statement

Patients or the public were not involved in the design, conduct, reporting, dissemination plans of our research.

\section{RESULTS}

\section{Sociodemographic and clinical data}

A total of 1249 patients were enrolled in the study. A total of 178 refused to participate. Thus, a total of 1071 patients completed the questionnaire (639 of CHB, 125 of CC, 85 of DC and 222 of HCC). In the HCC group, 71 patients were in the BCLC (0/A) stage, 60 in the BCLC (B) stage, 54 in the BCLC (C/D) stage and 34 with an unknown BCLC stage. There were statistically significant differences among the groups in age, gender, marital status, education level and occupation ( $p$ values below $0.05)$. The sociodemographic and disease characteristics of the patients are summarised in table 1.

\section{HRQOL and health utility scores}

Table 2 shows two summary and eight scale scores of SF-36v2 and health utility on CHB, CC, DC, HCC and different stages of HCC. The PCS scores of patients with CHB were found to be similar to those of the general population, while the MCS scores were lower than those of the general population. The mean scores of the CHB group were greater than 50 for PF, RP, BP and SF, while showing impaired HRQoL scores in the other four domains. Patients in CC had lower HRQoL and utility scores than those in $\mathrm{CHB}$, and more profound impairment was presented in advanced stages (DC and HCC). The difference in PCS scores between groups is greater than that of MCS scores. Comparing the eight scale scores among the four groups, no significant differences were found in BP, RE and MH scale scores between $\mathrm{CHB}$ and $\mathrm{CC}, \mathrm{MH}$ scale score between $\mathrm{CHB}$ and DC, MH scale score between $\mathrm{CC}$ and DC, MH and VT scale scores between CC and HCC, and GH, VT and MH scale scores between DC and HCC. For the scores among different stages of HCC, no significant differences were found except for the RP scale score between the early and terminal stages. See online supplemental table 1 for more information on the median and quartiles of each scale and summary score in the different groups.

The utility scores of patients grouped according to age, gender, whether they received antiviral treatment and the last surgery time are shown in table 3 . Significant differences were found in the patients with DC between the received antiviral therapy group and the not received antiviral therapy group and in the patients with HCC between the not undergone surgery group and the less than 6 months from the last surgery group. Apart from these, there were no significant differences between the other groups.

\section{Factors associated with $\mathrm{HRQOL}$}

The univariate regression analysis results reflect the associations between each summary score and 
Table 2 Mean short form-36 (SF-36) scores and health utility scores (SD) for each group of patients

\begin{tabular}{|c|c|c|c|c|c|c|c|}
\hline \multirow[b]{2}{*}{ SF-36 v2 } & \multirow[b]{2}{*}{$\begin{array}{l}\text { CHB } \\
(n=639)\end{array}$} & \multirow[b]{2}{*}{$\begin{array}{l}\text { CC } \\
(n=125)\end{array}$} & \multirow[b]{2}{*}{$\begin{array}{l}\text { DC } \\
(n=85)\end{array}$} & \multicolumn{4}{|l|}{ HCC } \\
\hline & & & & $\begin{array}{l}\text { BCLC (0/A) } \\
(n=71)\end{array}$ & $\begin{array}{l}\text { BCLC (B) } \\
(n=60)\end{array}$ & $\begin{array}{l}\text { BCLC (C/D) } \\
(n=54)\end{array}$ & $\begin{array}{l}\text { Overall } \\
(n=222)\end{array}$ \\
\hline PF & $53.97(6.00)$ & $49.17(10.92)^{\star}$ & $46.21(11.14)^{*} \dagger$ & 42.31 (13.22) & $37.48(16.20)$ & 39.93 (14.72) & $40.42(14.57)^{\star} \dagger \ddagger$ \\
\hline $\mathrm{RP}$ & $51.48(9.90)$ & $47.31(13.02)^{\star}$ & $39.39(15.31)^{*} \dagger$ & $35.73(17.04)$ & 34.68 (17.33) & 28.94 (16.34) & $34.54(16.95)^{\star} \dagger \ddagger$ \\
\hline $\mathrm{BP}$ & $50.61(9.17)$ & 49.59 (11.49) & $43.51(12.68)^{*} \dagger$ & $39.86(13.83)$ & 38.21 (14.74) & 36.84 (15.51) & $39.06(14.70)^{\star} \dagger \ddagger$ \\
\hline $\mathrm{GH}$ & 44.69 (10.75) & $40.87(10.79)^{\star}$ & $36.54(12.74)^{*} \dagger$ & $38.13(11.85)$ & 37.49 (11.12) & 37.67 (11.39) & $37.56(11.16)^{\star} \dagger$ \\
\hline VT & $46.18(10.45)$ & $42.00(11.42)^{\star}$ & $38.05(13.03)^{*} \dagger$ & 41.00 (14.38) & 40.99 (12.85) & $37.45(14.10)$ & $39.50(13.71)^{\star}$ \\
\hline SF & $50.03(10.44)$ & $47.63(12.70)$ & $42.91(13.61)^{*} \dagger$ & $39.92(15.09)$ & $37.02(14.23)$ & $37.08(15.65)$ & $38.49(15.44)^{*} \dagger \neq$ \\
\hline RE & $48.82(12.22)$ & $48.62(13.31)$ & $42.40(15.05)^{*} \dagger$ & $38.33(17.74)$ & 36.64 (18.42) & 33.01 (19.65) & $37.34(18.29)^{\star} \dagger \ddagger$ \\
\hline $\mathrm{MH}$ & $45.02(10.56)$ & 43.27 (12.35) & 42.97 (12.10) & 40.19 (15.36) & 41.33 (13.74) & 39.44 (15.42) & $40.49(14.61)^{\star}$ \\
\hline PCS & $52.86(6.848)$ & $48.56(10.03)^{\star}$ & $42.63(11.48)^{*} \dagger$ & $40.26(11.05)$ & $36.93(11.17)$ & $36.82(11.80)$ & $38.63(11.42)^{*} \dagger \neq$ \\
\hline MCS & 44.99 (11.30) & 43.76 (11.93) & $41.30(12.30)^{\star}$ & 39.61 (14.93) & 39.92 (13.19) & $37.17(16.70)$ & $39.23(14.85)^{\star} \dagger$ \\
\hline Utility & $0.773(0.131)$ & $0.750(0.146)$ & $0.683(0.128)^{*} \dagger$ & $0.656(0.145)$ & $0.635(0.132)$ & $0.615(0.128)$ & $0.640(0.133)^{*} \ddagger$ \\
\hline
\end{tabular}

*Significant different with chronic hepatitis B $(\mathrm{CHB})(\mathrm{p}<0.05)$.

†Significant different with compensated cirrhosis $(C C)(p<0.05)$.

$\ddagger$ Significant different with decompensated cirrhosis (DC) $(p<0.05)$.

BCLC, Barcelona clinic liver cancer; BP, bodily pain; GH, general health; HCC, hepatocellular carcinoma; MCS, mental componentsummary; $\mathrm{MH}$, mental health; PCS, physical component summary; PF, physical functioning; RE, role emotional; RP, role physical; SF, social functioning; VT, vitality.

sociodemographic and disease characteristics (table 4). Male sex, older age, lower education, occupation as a farmer and advanced stages of disease were significantly associated with worse summary scores.

For the multivariable regression analyses, sociodemographic characteristics were accounted for, and a stepwise regression model evaluated disease characteristics. Only variate disease status was selected for the three summary scores. Patients with CC had 3.603 points worse PCS (95\% CI -5.395 to -1.811$)$ and 1.679 points worse MCS (95\% CI -4.182 to 0.823$)$ compared with patients with CHB. Patients with DC had 9.110 points worse PCS (95\% CI -11.244 to -6.976$)$ and 4.130 points worse MCS (95\% CI -7.112 to -1.148 ) compared with patients with CHB. Patients with HCC had 12.772 points worse PCS (95\% CI -14.535 to -11.009$)$ and 6.951 points worse MCS (95\% CI -9.414 to -4.488 ) compared with patients with CHB.

\section{DISCUSSION}

HRQoL subjectively reported by the patient is a significant outcome in evaluating any intervention, mainly in patients with chronic or poorly curable diseases and is more relevant than the length of life, which is more of a concern for patients than longevity. ${ }^{22}{ }^{23}$ CHB-related disease is still the chronic liver disease with the heaviest disease burden in China; more than 50\% of liver-related deaths were caused by HBV infection in $2015 .^{24}$ Therefore, a comprehensive evaluation of HRQoL for CHBrelated diseases is valuable for identifying patients' needs and benefits of treatment and improvement of care and treatment services, that fit with the global hepatitis elimination targets set by WHO. ${ }^{12}$ This study is a multicentre and systematic study to measure HRQoL and utility scores of patients at all stages of CHB-related diseases in China. We found that the impairment of HRQoL in patients with CHB is mainly manifested in the psychological aspect, while physical HRQoL is similar to that of the general population, which is similar to the findings of Xi'an. ${ }^{6}$ The mental HRQoL impairment of patients with CHB has not been found in the USA, Hong Kong or Canada. ${ }^{7810}$ Patients in CC had worse HRQoL than those in $\mathrm{CHB}$, and more profound impairment was presented in advanced stages (DC and HCC). The results illustrate that the progress of the disease can cause the gradual impairment of HRQoL in patients with CHB-related disease. In addition, the mental HRQoL impairment in patients with CHB suggested that psychological support therapy should be strengthened, rather than just focusing on the normality of clinical indicators.

There is an increasing demand for the use of health utility in economic evaluations of health policy. ${ }^{25} 26$ Assessments of utility values for various health states in CHB disease are essential to estimate the costeffectiveness of the management of CHB disease. This study is also the first to evaluate the HRQoL and utility value of patients in early, middle and terminal HCC stages in China. We also calculated the utility value of different groups by reclassifying them according to age, gender, whether they had received antiviral treatment and the time of the last operation. The utility value of patients with DC receiving antiviral therapy is significantly lower than that of patients not receiving antiviral therapy. The reasons may be as follows. First, 


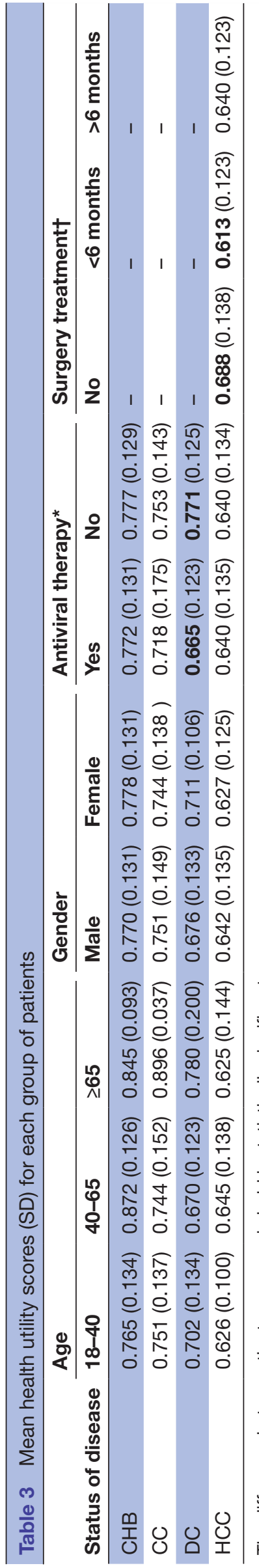

whether to receive antiviral treatment is generally based on the patient's condition, and patients with more serious conditions are more likely to receive antiviral treatment. Second, since the price of antiviral drugs in China has fallen sharply in recent years, it is unlikely that the antiviral treatment that should be accepted is unacceptable for reasons of drug prices. Significant difference was also observed between the not undergone surgery group and the less than 6 months from the last surgery group. This may be because the surgical trauma is severe, and the HRQoL of patients who have just undergone liver cancer surgery may decrease significantly. The results can also provide parameters for the cost-effectiveness analysis of HCC surgical treatments. For cost-effectiveness analyses of HCC early screening, treatment methods and drugs applicable to different stages of HCC, the utility parameter, which is an important instrument, generally came from data from other countries, which may affect the reliability of the research results to a certain extent. Nevertheless, the results of this study can provide reliable instrument support for the costeffectiveness analysis related to HCC in China.

The results of multiple linear regression analyses suggest that the advanced stages of disease have a negative impact on physical HRQoL, and lower education and advanced stages of disease have a negative impact on mental HRQoL. Hepatitis B infection may cause more anxiety and tension among patients with low education than among highly educated patients because of their lower awareness of the disease. Therefore, more attention should be paid to the psychology of patients with low education. Doctors should inform patients of disease-related knowledge when treating them to minimise patients' fear and anxiety, encouraging better HRQoL. This study did not observe significant differences in HRQoL between patients receiving antiviral therapy and those who did not receive antiviral therapy, regardless of the stage of disease, which is different from the study in Xiamen. ${ }^{27}$ We found that antiviral therapy was not associated with worse or better HRQoL. However, this study is a cross-sectional study, and the study in Xiamen was a follow-up study that may be better able to distinguish differences in HRQoL before and after antiviral treatment.

Our study has some limitations. All patients were recruited from three tertiary hospitals in two cities, in which the patients might have worse HRQoL. There is no strict tiered medical treatment system in China; most patients in tertiary hospitals can receive reasonable treatment in community hospitals. Therefore, it is unlikely that selection bias was caused by the patient source. This study is not a follow-up study, so it cannot be absolutely judged that the patient's life treatment will become worse as the disease progresses. Nevertheless, this cross-sectional study can suggest the above result. The utility scores were converted from SF-36v2 based on the SF-6D scoring model for the Hong Kong 


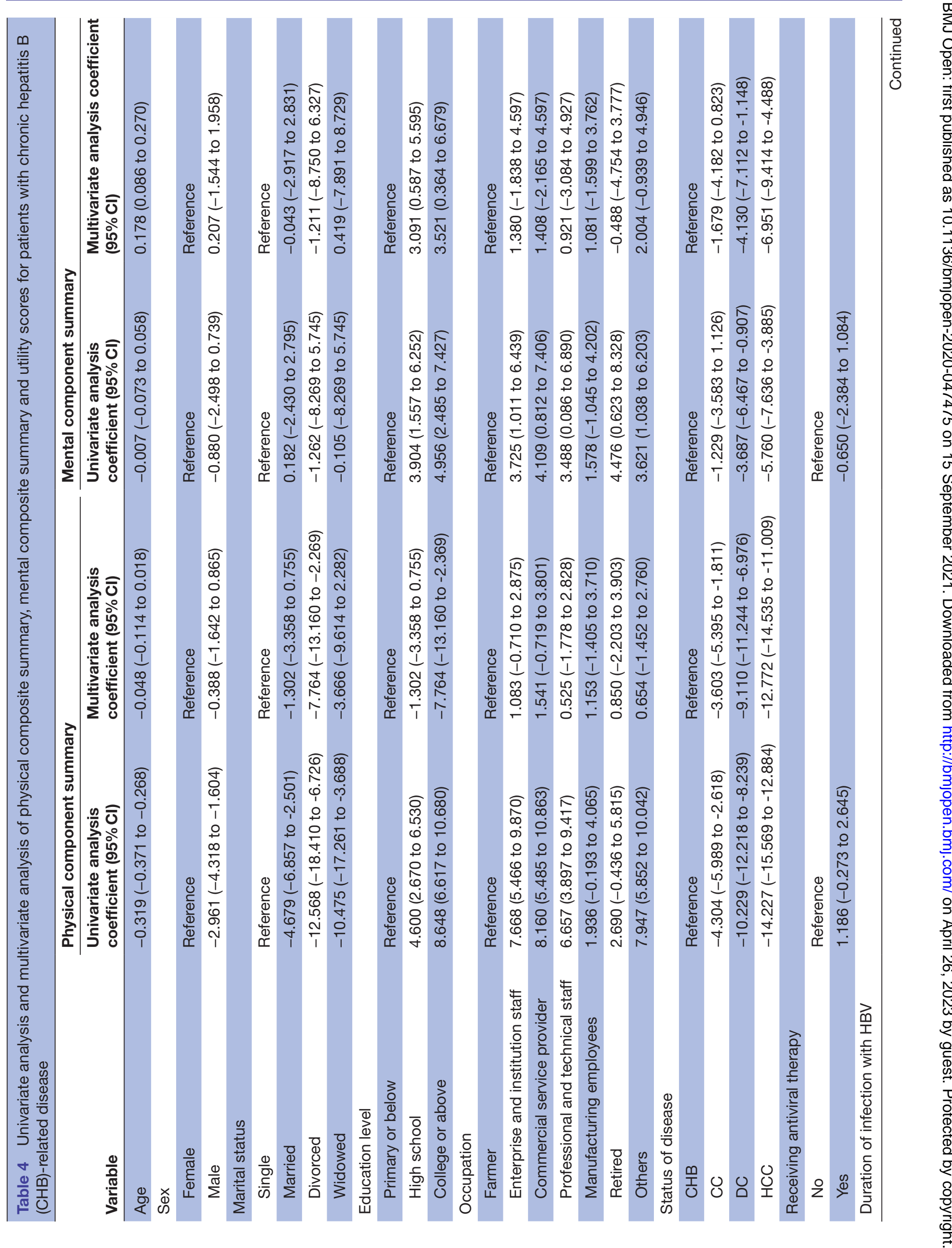


Chinese population, which might be different from the mainland Chinese population. However, the population of the Hong Kong model is the closest available to the mainland Chinese population. This also reminds us that the establishment of a model for the mainland Chinese population is urgently needed.

\section{CONCLUSION}

In summary, our study shows that the impairment of HRQoL is mainly reflected in the psychological aspect in the stage of CHB. The overall HRQoL will decrease as the disease progresses. Therefore, slowing the progress of CHB-related diseases can help patients maintain a better HRQoL. We not only focused on the normality of clinical indicators but also provided psychological support in the early stage of the disease, which is a key point to improve the disease-related quality of life. The utility results estimated in this study can provide an essential instrument for cost-effectiveness studies on CHB-related disease.

\section{Author affiliations}

${ }^{1}$ Department of Epidemiology and Health Statistics \& Henan Key Laboratory for Tumor Epidemiology, College of Public Health, Zhengzhou University, Zhengzhou, Henan, People's Republic of China

${ }^{2}$ State Key Laboratory of Esophageal Cancer Prevention \& Treatment, Zhengzhou University, Zhengzhou, Henan, People's Republic of China

${ }^{3}$ Beijing Institute of Hepatology, Beijing Youan Hospital, Capital Medical University, Beijing, People's Republic of China

${ }^{4}$ Hepatobiliary and Pancreatic Surgery, The First Affillated Hospital of Zhengzhou University, Zhengzhou, People's Republic of China

${ }^{5}$ Department of Oncology, Beijing Youan Hospital, Capital Medical University, Beijing, People's Republic of China

${ }^{6}$ Department of Interventional Radiology, The First Affillated Hospital of Zhengzhou University, Zhengzhou, People's Republic of China

${ }^{7}$ Henan Academy of Medical and Pharmaceutical Sciences \& BGI College, Zhengzhou University, Zhengzhou, Henan, People's Republic of China

Contributors MZ, JZ and SZ were responsible for study concept and design. MZ, YL, ZF, DS, XH, QY, ML and FR contributed to data acquisition and interpretation. MZ and YL performed all statistical analyses. MZ had main responsibility for writing the article. XW, LD, PW, HY, JS, XY, SZ, JZ provided comments on the manuscript. All authors read and approved the final manuscript.

Funding The study was funded by the Major Project of Science and Technology in Henan Province (161100311400).

Competing interests None declared.

Patient consent for publication Not required.

Ethics approval This study was approved by the ethics committee of Zhengzhou University (ZZURIB2019-001) and all participants of the cross-sectional study provided written informed consent.

Provenance and peer review Not commissioned; externally peer reviewed.

Data availability statement All data relevant to the study are included in the article or uploaded as supplementary information. No data are available.

Supplemental material This content has been supplied by the author(s). It has not been vetted by BMJ Publishing Group Limited (BMJ) and may not have been peer-reviewed. Any opinions or recommendations discussed are solely those of the author(s) and are not endorsed by BMJ. BMJ disclaims all liability and responsibility arising from any reliance placed on the content. Where the content includes any translated material, BMJ does not warrant the accuracy and reliability of the translations (including but not limited to local regulations, clinical guidelines, terminology, drug names and drug dosages), and is not responsible for any error and/or omissions arising from translation and adaptation or otherwise. 
Open access This is an open access article distributed in accordance with the Creative Commons Attribution Non Commercial (CC BY-NC 4.0) license, which permits others to distribute, remix, adapt, build upon this work non-commercially, and license their derivative works on different terms, provided the original work is properly cited, appropriate credit is given, any changes made indicated, and the use is non-commercial. See: http://creativecommons.org/licenses/by-nc/4.0/.

ORCID iD

Meng Zhang http://orcid.org/0000-0003-2971-5109

\section{REFERENCES}

1 World Health Organisation. Combating hepatitis B and C to reach elimination by 2030. Advocacy brief, 2016. Available: https://www. who.int/publications/i/item/combating-hepatitis-b-and-c-to-reachelimination-by-2030

2 World Health Organisation. Global health sector strategy on viral hepatitis, 2016-2021: towards ending viral hepatitis, 2016. Available: https://www.who.int/publications/i/item/WHO-HIV-2016.06

3 Cui F, Shen L, Li L, et al. Prevention of chronic hepatitis B after 3 decades of escalating vaccination policy, China. Emerg Infect Dis 2017;23:765-72.

4 Wang $\mathrm{H}$, Men $\mathrm{P}$, Xiao $\mathrm{Y}$, et al. Hepatitis B infection in the general population of China: a systematic review and meta-analysis. BMC Infect Dis 2019;19:811.

5 Cella D, Stone AA. Health-Related quality of life measurement in oncology: advances and opportunities. Am Psychol 2015;70:175-85.

6 Zhuang G, Zhang M, Liu Y, et al. Significant impairment of healthrelated quality of life in mainland Chinese patients with chronic hepatitis B: a cross-sectional survey with pair-matched healthy controls. Health Qual Life Outcomes 2014;12:101.

7 Bondini S, Kallman J, Dan A, et al. Health-related quality of life in patients with chronic hepatitis B. Liver Int 2007;27:1119-25.

8 Lam ETP, Lam CLK, Lai CL, et al. Health-related quality of life of southern Chinese with chronic hepatitis B infection. Health Qual Life Outcomes 2009;7:52.

9 Gao R, Gao F, Li G, et al. Health-Related quality of life in Chinese patients with chronic liver disease. Gastroenterol Res Pract 2012;2012:1-7.

10 Younossi ZM, Stepanova M, Younossi I, et al. Patient-reported outcomes in patients chronic viral hepatitis without cirrhosis: the impact of hepatitis B and C viral replication. Liver Int 2019;39:1837-44.

11 Evon DM, Lin H-HS, Khalili M, et al. Patient-reported outcomes in a large North American cohort living with chronic hepatitis $B$ virus: a cross-sectional analysis. Aliment Pharmacol Ther 2020;51:457-68.
12 Wang K, Li M, Qin J, et al. Serological biomarkers for early detection of hepatocellular carcinoma: a focus on autoantibodies against tumor-associated antigens encoded by cancer driver genes. Cancers 2020;12:e127.

13 Kim SY, An J, Lim Y-S, et al. Mri with liver-specific contrast for surveillance of patients with cirrhosis at high risk of hepatocellular carcinoma. JAMA Oncol 2017;3:456-63.

14 Lima PH, Fan B, Bérubé J. Cost-Utility analysis of imaging for surveillance and diagnosis of hepatocellular carcinoma. AJR Am J Roentgenol 2019;17:1-9.

15 Schackman BR, Gold HT, Stone PW, et al. How often do sensitivity analyses for economic parameters change cost-utility analysis conclusions? Pharmacoeconomics 2004;22:293-300.

16 European Association For The Study Of The Liver. EASL clinical practice guidelines: management of chronic hepatitis B. $J$ Hepatol 2009;50:227-42.

17 Wang HM. The influence of common chronic diseases on patients' quality of life in Chinese and German communities. 1st ed. Zhejiang, China: Zhejiang University Press, 2015: 207-8.

18 Brazier J, Roberts J, Deverill M. The estimation of a preferencebased measure of health from the SF-36. J Health Econ 2002;21:271-92.

19 Lam CLK, Brazier J, McGhee SM. Valuation of the SF-6D health states is feasible, acceptable, reliable, and valid in a Chinese population. Value Health 2008;11:295-303.

20 Chinese Society of Infectious Diseases, Chinese Medical Association, Chinese Society of Hepatology, Chinese Medical Association. [The guidelines of prevention and treatment for chronic hepatitis B (2019 version)]. Zhonghua Gan Zang Bing Za Zhi 2019;27:938-61.

21 Bruix J, Sherman M, Practice Guidelines Committee, American Association for the Study of Liver Diseases. Management of hepatocellular carcinoma. Hepatology 2005;42:1208-36.

22 Gandhi S, Khubchandani S, lyer R, et al. Quality of life and hepatocellular carcinoma. J Gastrointest Oncol 2014;5:296-317.

23 Qiao C-X, Zhai X-F, Ling C-Q, et al. Health-Related quality of life evaluated by tumor node metastasis staging system in patients with hepatocellular carcinoma. World J Gastroenterol 2012;18:2689-94.

24 Sarin SK, Kumar M, Eslam M, et al. Liver diseases in the Asia-Pacific region: a Lancet Gastroenterology \& Hepatology Commission. Lancet Gastroenterol Hepatol 2020;5:167-228.

25 Higgins AM, Harris AH. Health economic methods: costminimization, cost-effectiveness, cost-utility, and cost-benefit evaluations. Crit Care Clin 2012;28:11-24.

26 Angevine PD, Berven S. Health economic studies: an introduction to cost-benefit, cost-effectiveness, and cost-utility analyses. Spine 2014;39:S9-15.

27 Xue X, Cai S, Ou H, et al. Health-related quality of life in patients with chronic hepatitis $B$ during antiviral treatment and off-treatment. Patient Prefer Adherence 2017;11:85-93. 